\title{
NON-DUALISM AND INFORMATION SYSTEMS RESEARCH
}

\author{
Abhijit Jain \\ Temple University
}

\begin{abstract}
This paper makes a case for the grounding of information systems research within theoretical frameworks that reject the idea of subject-object dualism. In support, two rationales are offered.

(1) Research in information systems exhibits an overwhelming dominance of positivistic research methodologies. Such positivistic research approaches have their roots in the scientific method, and in the attempt to transplant the scientific method from the context of the natural sciences to the context of the social sciences. Further, according to various theorists, the scientific method has its roots in the concept of subject-object dualism put forward by Descartes and others. Thus, this paper argues that IS researchers who wish to resist the current orthodoxy, and who seek to advance a nonpositivistic research program, may find it useful to anchor their research within paradigmatic and theoretical frameworks that reject the concept of subjectobjectdualism.

(2) Research into differences in cognitive processes among distinct cultures suggests that there are differences between Western and Eastern ways of thinking. The Eastern mindset is typically more sympathetic to the notion of subject-object non-dualism than the Western mindset. This difference may have implications for the design of IS that rely heavily on modes of human cognition (e.g., knowledge management or decision support systems). This suggests that when considering certain cultural or cross-cultural contexts, IS researchers may benefit from grounding their assumptions within non-dualistic paradigmatic and theoretical frameworks.
\end{abstract}

\section{INTRODUCTION}

The notion of subject-object dualism deeply permeates the existential foundations of much human activity, at least in the West. From the way communication is structured (i.e., in the rules of grammar) to the way in which epistemological and ontological 
notions are constructed (cf. Burrell and Morgan 1979), the impress of subject-object dualism is ineluctable. Consequently, instead of being understood as an artifact of a particular mode of thinking, dualism has been reified to the status of fact.

A fallout of this situation is that the scientific method, which the research community relies on heavily, is thoroughly immersed in assumptions emanating from implicit acquiescence of subject-object dualism (Berman 1989; Capra 1975).

However, this dualistic mode is not the only available mode of thinking. There also exist non-dualistic frameworks within which understanding can be established. In order to counter the hegemony of dualism, this paper argues for grounding information systems research within non-dualistic paradigmatic frameworks. In support of this contention, the paper discusses the potential utility of framing IS research in nondualistic paradigmatic frameworks when conducting (1) non-positivistic IS research and (2) IS research in certain cultural and cross-cultural contexts.

The rest of this paper is organized as follows: Section 2 explicates the utility of grounding non-positivist research in non-dualistic paradigmatic frameworks, and includes a discussion of how subject-object dualism is considered to have contributed to the development of the scientific method. Section 3 elucidates the utility of nondualistic paradigmatic frameworks to IS research in certain cultural and cross-cultural contexts. Section 4 offers concluding remarks.

\section{GROUNDING NON-POSITIVIST IS RESEARCH IN NON-DUALISM}

\subsection{The Dominance of Positivism in the Current Orthodoxy of IS Research}

In the prevailing body of information systems (IS) research, positivistic research methodologies and philosophical assumptions overwhelmingly dominate the available range of methodologies and assumptions (cf. Mingers 2001; Nandhakumar and Jones 1997; Orlikowski and Baroudi 1991). This has led to criticism from researchers who seek an alternative, more diverse order, in which multiple research approaches-that subscribe to different epistemological, ontological, and methodological assumptionsan coexist and attain significance (cf. Klein and Lyytinen 1985, Mingers 2001; Orlikowski and Baroudi 1991).

Researchers have criticized positivistic methodology for subscribing to a dogma of scientism, which emphasizes objectivity and methodological rigor over contextual relevance (cf. Klein and Lyytinen 1985). Consequently, researchers have questioned whether such scientistic methods are appropriate for social science research (ibid) and have called for increased consideration of alternative approaches, such as the interpretivist and the critical, in order to facilitate "exploration of phenomena from diverse frames of reference" (Orlikowski and Baroudi 1991, p.2). 


\subsection{Dualism: A Root of Positivism and the Scientific Method}

According to a number of modern Western scientists, philosophers, and historians of science, modern Western scientific philosophy has been profoundly influenced by the concept of subject-object dualism (cf. Barrett 1986; Berman 1989; Capra 1975; Clapp et al. 1962; Wallace 1989, 2000). Dualistic themes have been espoused by various philosophers, going all the way back to, and including, Plato. However, the most prominent and influential proponent of dualism is generally regarded to be Descartes, who proposed that there was a dichotomy between the human mind and material things (such as the human body). According to this theory of subject-object dualism, objective reality consisted of the physical, material world, whereas everything that was not physical or material, e.g., feeling, belonged to a subjective realm. Further, according to Descartes, (1) a clean separation between subject and object was possible; (2) the objective realm was the only legitimate domain of enquiry; and (3) all of nature could be understood by studying it objectively (cf. Berman 1989; Capra 2000; Clapp et al. 1962). Knowledge obtained in this way was presumed to be better because it was objective and did away with subjective elements that were not considered particularly relevant. Such thinking gave rise to the concept of the scientific method, according to which scientists were expected to impersonally observe and measure phenomena in order to understand them. Empiricism, it was thought, transcended the limits of human subjectivity and gave an accurate account of the world. Since such inquiry was objective it was considered value-neutral and apolitical. Thus science was considered the unbiased way to solve problems, and scientists discovered the truth by unsympathetically observing and measuring reality.

As it happened, the scientific method proved remarkably successful in conducting inquiry into natural sciences such as physics, chemistry, and astronomy. This eventuality lent credibility to Descartes' metaphysical speculations, and they gradually took on the status of being fact. Over time, dualistic thinking led to objective reality acquiring primacy over subjective experience. Supposedly, reality was objectively given, and considered always true. Human contextual experience, on the other hand, was subjective, fickle, subject to continual change, and not considered worth studying. Human beings were thus regarded as spectators, irrelevant bystanders to a grand mathematical, mechanistic system that was the essence of reality. The elevation of the objective over the subjective became complete.

Subsequently, scientific thinking morphed into a dogma of scientism (Klein and Lyytinen 1985), and it gradually came to be believed that the scientific method was the only appropriate and legitimate path to knowledge in every context and domain of inquiry, prompting theorists such as Hobbes and Comte to advocate the use of scientistic, positivistic methods for the investigation of social phenomena (cf. Hirschheim 1985; Klein and Lyytinen 1985).

Thus, the dominance of positivism in the prevailing order can be traced to the successes of the scientific method in conducting inquiry into the natural sciences, and to subsequent attempts to apply the scientific method to research in the domain of the 
social sciences (cf. Klein and Lyytinen 1985). Further, the scientific method is said to have arisen out of the concept of subject-object dualism. Therefore, according to this chain of reasoning, subject-object dualism may be considered to be a root of positivism (or the scientific method).

\subsection{The Utility of Non-Dualism to Non-Positivist IS Research}

If subject-object dualism is a root of the scientific method, and by extension a root of positivism; ifpositivism dominates the current milieu of IS research; and if a change in this status quo is desirable; then a good starting place for a research program that seeks to effect a change in this status-quo should be from within philosophical frameworks that reject the concept of subject-object dualism and belie the suggestion that a clean separation between subject and object is possible. Thus researchers who seek to advance non-positivistic research programs should find it valuable to anchor their research within paradigmatic and theoretical frameworks that reject the concept of subject-object dualism.

There are several available, implicitly non-dualistic, philosophical frameworks that could prove useful in this regard. For instance, Kant (1977) espoused a theory according to which cognition was antecedent to experience, and the reception of sensory experience was necessarily determined according to preexisting concepts that existed in the mind. Thus, objective observation was unfeasible, and the subject was inextricably linked to the experience. Hegel's (1967) philosophy of absolute idealism refuted the traditional epistemological distinction between object and subject, and posited that material things existed only according how they were perceived. Heidegger (cf. Dreyfus 1991) questioned the idea that experience could be explained in terms of relationships between independent subjects and objects. He posited a "more fundamental way of being-in-the-world that cannot be understood in subject/object terms" (Dreyfus 1991, p. 5), and sought to emphasize the role of "social context as the ultimate foundation of intelligibility" (ibid, p. 7). In the case of Zen philosophy, the key aim is "the overcoming of all dualistic discrimination" (DeMartino 1981, p. 80). According to a Zen koan, a customer asked a butcher which piece of meat was best. The butcher replied, "Each of our pieces of meat is the best." Which piece is best would depend on a myriad of variables, such as what the customer prefers, and how one chose to define the word best; thus implying that everything exists only in relation to the observer.

IS researchers seeking to employ non-positivistic methodologies should benefit from anchoring their research in non-dualistic philosophical frameworks because by doing so they can avoid having to subordinate their research assumptions to the assumptions of a dualistic epistemology or ontology; and they can thus steer clear of those influences inherent in the concept of subject-object dualism that have led to the emergence of positivism. 


\section{GROUNDING IS RESEARCH IN NON-DUALISM IN CERTAIN CULTURAL CONTEXTS}

Research into differences in cognitive processes among distinct cultures suggests that there is significant divergence between Western and Eastern ways of thinking (Capra 2000; Nisbett 2003). According to a major study devoted to this subject (Nisbett, 2003), the Western mindset is more reductionist (i.e., is more comfortable dealing with parts than with wholes), places greater value on consistency, and is more inclined toward consideration of objective attributes. In contrast, the Eastern is mindset is more holistic, more willing to accommodate contradiction and more predisposed towards consideration of subjective context. Additionally, the Western mind generally values individualism and distinctiveness, while, conversely, the Eastern mind usually places value on consensus and harmony. According to researchers, when such cognitive and attitudinal differences are aggregated, they indicate that the Western mindset is normally more predisposed toward the concept of subject-object dualism, whereas the Eastern mindset is typically more sympathetic to the notion of subject-object non-dualism (Capra 2000; Nisbett 2003).

These propositions have significant implications for the design of information systems that deeply engage human cognitive processes, and they imply that it may be naïve to attempt to transplant systems, such as knowledge management or decision support systems (among other kinds of IS), that have been developed in one cultural context (say the West) onto the other cultural context (say the East). Further, it may not be appropriate for researchers to approach IS research in certain cultural contexts (i.e., where mindsets are more inclined to non-dualistic thinking) from within dualistic paradigmatic frameworks. As explained in section 2, positivism and the scientific method have their roots in such a dualistic framework. Thus, when considering certain cultural or cross-cultural contexts where non-dualistic thinking is involved, IS researchers may benefit from framing research and development activities within non-dualistic paradigmatic and theoretical frameworks that correspond better to the cultural context at hand.

\section{CONCLUDING REMARKS}

This paper has sought to describe the potential utility of non-dualistic philosophical frameworks to IS research. In doing so, this paper discusses why paradigmatic and theoretical frameworks that reject or belie apriori assumptions about subject-object dualism may be useful for the purpose of advancing non-positivistic research, and for conducting IS research and development activities in certain cultural or cross-cultural contexts.

\section{REFERENCES}

Barrett, W. Death of the Soul: From Descartes to the Computer, Garden City, NY: Anchor Press, 1986.

Berman, M. Coming to our Senses: Body and Spirit in the Hidden History of the West, New York: Simon and Schuster, 1989. 
Burrell, L., and Morgan, G. Sociological Paradigms and Organizational Analysis, London: Heinemann Educational Books, 1979.

Capra, F. The Tao of Physics, Boston: Shambhala, 1975.

Clapp, J. G.; Philipson, M.; and Rosenthal, H. M. (Eds.). Foundations of Western Thought: Six Major Philosophers, New York: Knopf, 1962.

DeMartino, R. J. "The Zen Understanding of the Initial Nature of Man," in N. Katz (Ed.), Buddhist and Western Philosophy, Atlantic Highlands, NJ: Humanities Press, 1981, pp. 8120.

Dreyfus, H. Being-in-the-World: A Commentary on Heidegger's Being and Time, Division I, Cambridge, MA: MIT Press, 1991.

Hegel, G. W. F. The Phenomenology ofMind, J. B. Bailie (Trans.), New York: Harper \& Row, 1967.

Hirschheim, R. "Information Systems Epistemology: An Historical Perspective," in E. Mumford, R. Hirschheim, G. Fitzgerald, and A. T. Wood-Harper (Eds.), Research Methods in Information Systems, Amsterdam: North-Holland, 1985, pp. 9-33.

Kant, I. Prolegomena to Any Future Metaphysics That Will Be Able to Come Forward as Science: A Revision of the Paul Carus Translation by James Ellington, Indianapolis: Hackett Publishing Company, 1977.

Klein, H. K., and Lyytinen, K. "The Poverty of Scientism in Information Systems," in E. Mumford, R. Hirschheim, G. Fitzgerald, and A. T. Wood-Harper (Eds.), Research Methods in Information Systems, Amsterdam: North-Holland, 1985, pp. 123-151.

Mingers, J. "Combining IS Research Methods: Towards a Pluralist Methodology," Information Systems Research (12:3), 2001, pp. 240-259.

Nandhakumar, J., and Jones, M. "Too Close for Comfort? Distance and Engagement in Interpretive Information Systems Research,” Information Systems Journal (7:2), 1977, pp. 109131.

Nisbett, R. E. The Geography ofThought: How Asians and Westerners Think Differently-and Why, London: Free Press, 2003.

Orlikowski, W. J., and Baroudi, J. J. "Studying Information Technology in Organizations: Research Approaches and Assumptions,"Information Systems Research (2:1), 1991, pp. 1-28.

Wallace, B. A. Choosing Reality: A Contemplative View of Physics and the Mind, Boston: Shambhala, 1989.

Wallace, B. A. The Taboo of Subjectivity: Toward a New Science of Consciousness, Oxford: Oxford University Press, 2000.

\section{ABOUT THE AUTHOR}

Abhijit Jain is a doctoral candidate in management information systems at Temple University, Philadelphia. His research interests include e-government, and defense and medical information systems. He has had papers accepted at conferences such as the International Conference on Information Systems, the Hawaii International Conference on System Sciences, and the Americas Conference on Information Systems. He can be reached at jain@ temple.edu. 